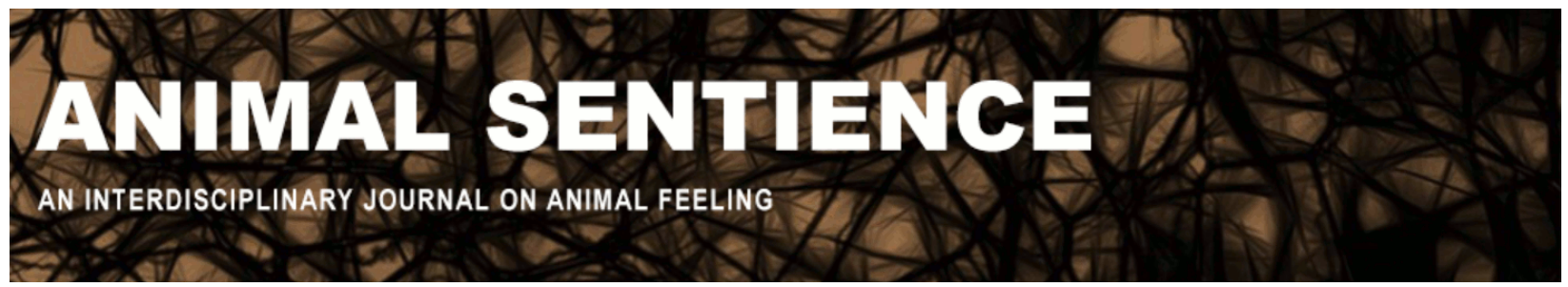

Woodruff, Michael L. (2016) Implicit mental processes are an improbable basis for personhood. Animal Sentience 10(2)

DOI: $10.51291 / 2377-7478.1123$

Date of submission: 2016-07-15

Date of acceptance: 2016-07-18 (c) 


\title{
Implicit mental processes are an improbable basis for personhood
}

Commentary on Rowlands on Animal Personhood

\author{
Michael L. Woodruff \\ East Tennessee State University
}

\begin{abstract}
Rowlands argues that animals have implicit pre-reflective awareness and that this is adequate to create the unity of conscious thought required for personhood. For him prereflective awareness does not include intentionality and is probably an unconscious process. I suggest that his sense of implicit leads to significant difficulties for his argument and that including intentionality in the definition of a first-person perspective provides a stronger base for viewing animals as persons.
\end{abstract}

Michael L. Woodruff is Professor Emeritus of
Biomedical Sciences and of Psychology at East
Tennessee State University. Author of more
than 120 professional publications, his
research interests include cognitive
neuroscience and the philosophy of mind.
https://etsu.academia.edu/MikeWoodruff

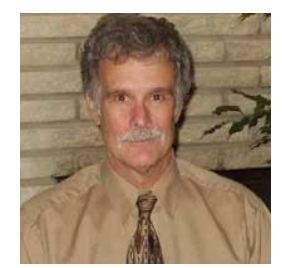

Professor Rowlands (2016) argues that there is a legitimate metaphysical basis for animal personhood. He frames his argument within Locke's conception of personhood as expressed in the Essay on Human Understanding: "we must consider what person stands for; which, I think, is a thinking intelligent being, that has reason and reflection, and can consider itself as itself, the same thinking thing in different times and places; which it does only by that consciousness, which is inseparable from thinking..." (Locke 1996, §9, p. 138). Rowland focuses on the italicized part of this quote, noting that to be a person requires a "mental life" and a sense of "unity," i.e., "the same thinking thing." He acknowledges that this requirement "...ties the issues of personhood and self-awareness." Therefore, "If animals are not self-aware, they are not persons."

It is generally accepted that personhood requires "reflective self-awareness," allowing a subject to recognize that its diverse mental states "all belong together." Reflective self-awareness is intentional, i.e., for it to exist the subject's body and/or mental life must be an object of its higher-order intentional acts, hence it requires higher-order thought processes.

It is often thought that animals lack reflective self-awareness and therefore cannot be persons. Rowlands argues that personhood should be extended to animals. However, he does not do so by contending that animals do have reflective self-awareness. Rather, he emphasizes that personhood requires a sense of mental unity and argues that implicit self-awareness is adequate for production of that unity. Thus, personhood should be extended to any species that possesses implicit self-awareness. On Rowlands's view, animals have a kind of implicit selfawareness that he, following Sartre, calls pre-reflective self-awareness. He argues that animals 
do have pre-reflective self-awareness and are hence persons. The core of his argument is that the perception of the affordances of an object such as a chair creates an awareness of self in the observer without the need for the observer to perceive (be aware of) its own body. This awareness does not require higher-order thought processes.

While I am sympathetic to Rowlands's objective, I do not find that his argument works. Here's why:

The idea that pre-reflective awareness is implicit is central to Rowlands's argument, yet his only reference to his meaning of implicit is "the category of the implicit is not the same as that of the unconscious." I find this statement ambiguous. It can be interpreted as meaning that implicit mental contents are not the same thing as unconscious contents, or it may mean that implicit mental contents are not unconscious, i.e., they are conscious. Either interpretation creates difficulties for Rowlands's argument. If implicit does not mean unconscious, then either the unity in mental life produced by pre-reflective awareness is unconscious (in which case, it is difficult to see how such a unity could contribute to the sense of "being the same thinking thing") or the process by which pre-reflective awareness causes the unity in mental life needs to be explained. Rowlands is silent on these points.

If Rowlands means that implicit mental contents are conscious, then a defense of this sense of "implicit" is needed, as both in philosophy (e.g., Polanyi 1961) and in cognitive psychology (e.g., Reber 1993) implicit mental processes (also called "tacit" processes) are almost universally regarded as unconscious. Indeed, there is a voluminous research literature indicating that implicit processes of various sorts exert significant influence over cognition and behavior (e.g., Haidt 2012), but the processes themselves remain "refractory to invasion by consciousness" (Reber 1992, p. 97). Thus, either Rowland needs to defend a meaning of implicit that allows it to be conscious, or the problem noted above arises. That is, how can an unconscious process of pre-reflexive awareness account for the ability to determine whether, to use Rowlands's example, thoughts such as "the sky is blue," "it will rain later," or "I will take the boat to the island" occur in only one person, or in multiple persons?

In sum, I do not agree with Rowlands that "[a] person exists wherever there is a unified mental life." While a unified mental life is necessary for a person to exist, it is not sufficient. I also think it is an error to remove intentionality and higher-order thought processes from the criteria for what constitutes a person. In partial agreement with Baker (2013), a first-person perspective is needed for personhood and, at a minimum, a first-person perspective requires intentionality. Baker identifies two varieties of first-person perspective, rudimentary and robust. A rudimentary first-person perspective exists when a subject has "the capacity to interact, consciously and intentionally, with the environment from a particular location (the 'origin' of the perceptual field)" (Baker 2013, p. 170). A subject shows a robust first-person perspective, and is considered to have personhood when there is "the capacity to think of oneself, conceived in the first person, as the object of one's thought" (Ibid, p. xix). 
Baker goes on to suggest that only humans with language have a robust first-person perspective and are, therefore, persons. I disagree on this point. What might constitute evidence of the "capacity to think of oneself, conceived in the first-person" is open to empirical definition and investigation; language should not constitute the defining criterion for a robust first-person perspective.

To conclude, I think that efforts to define better what might contribute to generating a robust first-person perspective have more potential for extending personhood to animals than attempting to use non-conscious processes to explain unity in mental life.

\section{References}

Baker, L. R. (2013) Naturalism and the first-person perspective. (Oxford: Oxford University Press)

Haidt, J. (2012) The righteous mind: why good people are divided by politics and religion. (New York: Pantheon)

Locke, J. (1996) Essay concerning human understanding. Winkler, K. P. (Ed.) (Indianapolis: Hackett Publishing)

Polanyi, M. (1961) Knowing and being. Mind, 70, 458-470

Reber, A. S. (1993) Personal knowledge and the cognitive unconscious. Polanyiana, 3, 97-115

Rowlands, M. (2016) Are animals persons? Animal Sentience 2016.101 